\title{
Pengaruh Laju Injeksi Doping Sulfur terhadap Aktivitas Fotokatalis Nanotitania Menggunakan Metode Sol Gel
}

\author{
Delfi Oktavia Amrani ${ }^{(1, a)^{*}}$, Posman Manurung ${ }^{(1, b)}$, Pulung Karo-Karo ${ }^{(2, c)}$ \\ Contoh : ${ }^{(1)}$ Jurusan Fisika, Universitas Lampung, Bandar Lampung, Indonesia, 35141 \\ Email :(a*) delfioktavia0@gmail.com, ${ }^{(b)}$ posman65@unila.ac.id, ${ }^{(c)}$ pkkkacaribu@yahoo.com
}

Diterima (15 Juli 2019), Direvisi (01 Agustus 2019)

\begin{abstract}
Synthesis of sulfur doped titania $\left(\mathrm{S}_{-} \mathrm{TiO}_{2}\right)$ was carried out through sol-gel method. Titanium isopropoxide (TTIP), tween-80, isopropanol and sulfuric acid $\left(\mathrm{H}_{2} \mathrm{SO}_{4}\right)$ as a source of sulfur doping were used as raw material. The aimed of this research is to study the effect of the rate of sulfur doping injection by using an injection pump toward $\mathrm{S}-\mathrm{TiO}_{2}$ photocatalyst activity. Titania was calcined at temperatur of $450{ }^{\circ} \mathrm{C}$ for 5 hours. The sintered samples were tested for photodegradation of remazol yellow under UV irradiation. Physical characteristics were analyzed using transmission electron microscopy (TEM) and UV-Vis Spectrophotometer. The result of the UV-Vis spectrophotometer showed that the rate of sulfur doping injection has an effect on increasing photocatalysts activity of $\mathrm{TiO}_{2}$. Maximum photocatalysts activity was obtained in sample with an injection rate of $4 \mathrm{ml} / 30$ minutes with the particle size is $(7,1 \mathrm{~nm} \pm 1,9 \mathrm{~nm})$.
\end{abstract}

Keywords: photodegradation, remazol yellow, sulfur doped, titania.

\begin{abstract}
Abstrak. Sintesis titania doping sulfur $\left(\mathrm{S}-\mathrm{TiO}_{2}\right)$ dilakukan melalui metode sol-gel. Titanium isopropoksida (TTIP), tween-80, isopropanol dan asam sulfat $\left(\mathrm{H}_{2} \mathrm{SO}_{4}\right)$ sebagai sumber doping sulfur digunakan sebagai bahan utama. Penelitian ini bertujuan untuk mempelajari pengaruh laju injeksi doping sulfur menggunakan pompa injeksi terhadap aktivitas fotokatalis $\mathrm{S}_{-} \mathrm{TiO}_{2}$. Serbuk titania dikalsinasi pada suhu $450{ }^{\circ} \mathrm{C}$ selama 5 jam dan diuji untuk fotodegradasi remazol kuning di bawah sinar UV. Karakteristik fisika dianalisis menggunakan transmission electron microscopy (TEM) dan Spektrofotometer Uv-Vis. Hasil pengujian spektrofotometer UV-Vis menunjukkan bahwa laju injeksi doping sulfur pada $\mathrm{TiO}_{2}$ berpengaruh terhadap peningkatan aktivitas fotokatalis $\mathrm{TiO}_{2}$. Aktivitas fotokatalis maksimum diperoleh pada sampel dengan variasi laju injeksi doping $4 \mathrm{ml} / 30$ menit dengan ukuran partikel sebesar $(7,1 \mathrm{~nm} \pm 1,9 \mathrm{~nm})$.
\end{abstract}

Kata kunci: fotodegradasi, remazol kuning, doping sulfur, titania.

\section{PENDAHULUAN}

Titanium dioksida $\left(\mathrm{TiO}_{2}\right)$ merupakan nanomaterial yang bersifat semikonduktor yang dapat menghantarkan listrik, sifat logam yang kuat, ringan dan memiliki kerapatan yang rendah [1]. $\mathrm{TiO}_{2}$ mempunyai tiga polimorf yaitu anatase, rutil, dan brukit. Rutil adalah fase stabil suhu tinggi yang memiliki celah energi sebesar 3,0 eV, anatase terbentuk pada suhu yang lebih rendah dengan celah energi sebesar 3,2 eV [2], [3].

$\mathrm{TiO}_{2}$ memiliki keunggulan antara lain murah, non-toksik dan kestabilannya tinggi apabila dikenai cahaya [4]. Dengan demikian, $\mathrm{TiO}_{2}$ banyak digunakan sebagai bahan fotokatalis. Dalam aplikasinya sebagai fotokatalis, umumnya fasa anatase yang digunakan karena memiliki aktivitas fotokatalis yang lebih tinggi dibandingkan fasa rutil dan brukit [5]-[7]. 
Kemampuan fotokatalitik meningkat seiring dengan meningkatnya kinerja sistem yang dipengaruhi oleh modifikasi morfologi dan kimia. Modifikasi morfologi terjadi melalui peningkatan struktur nanokristal, luas permukaan dan porositas. Sedangkan modifikasi kimia terjadi melalui penambahan komponen di dalam struktur $\mathrm{TiO}_{2}$ [8]. Sifat fotokatalis nanotitania juga dipengaruhi oleh ukuran partikel [9]. Penurunan ukuran butir partikel menunjukkan adanya peningkatan luas permukaan yang mengarah pada tingginya aktivitas fotokatalis [10].

Penelitian mengenai modifikasi nanopartikel $\mathrm{TiO}_{2}$ dan aplikasinya sudah dikembangkan dengan berbagai metode, salah satunya adalah metode sol-gel. Metode sol-gel banyak digunakan dalam mempreparasi material oksida logam karena dapat menghasilkan partikel berukuran nano dan memiliki aktivitas fotokatalis yang tinggi. [11] Beberapa peneliti melakukan modifikasi nano $\mathrm{TiO}_{2}$ dengan beberapa perlakuan, salah satunya yaitu dengan penambahan dopan pada $\mathrm{TiO}_{2}$.

Dopan diberikan pada suatu unsur atau senyawa dengan tujuan menghasilkan katalis baru dan dapat aktif dibawah cahaya tampak. Salah satu dopan yang digunakan dalam modifikasi $\mathrm{TiO}_{2}$ yaitu sulfur [12][15]. Sulfur memiliki stabilitas yang tinggi ketika didoping ke dalam $\mathrm{TiO}_{2}$ seperti yang dilaporkan oleh Periyat et al., (2008).

Penambahan sulfur secara perlahan pada $\mathrm{TiO}_{2}$ dapat meningkatkan aktivitas fotokatalis dan menurunkan ukuran partikel $\mathrm{TiO}_{2}$ [13]. Sehingga pada penelitian ini dilakukan modifikasi $\mathrm{TiO}_{2}$ doping sulfur dengan variasi laju injeksi doping sulfur dari $\mathrm{H}_{2} \mathrm{SO}_{4}$ menggunakan pompa injeksi yang bertujuan untuk mengetahui pengaruh laju injeksi doping sulfur terhadap aktivitas fotokatalis $\mathrm{TiO}_{2}$ menggunakan metode solgel.

\section{METODE PENELITIAN}

Alat yang digunakan pada penelitan ini adalah gelas sampel, mikro pipet, pengaduk magnetik, neraca digital, mortar akik, oven, furnace, lampu UV Ultra Vitalux 230 E27 Osram dan pompa injeksi XB-500. Sedangkan bahan yang digunakan adalah titanium (IV) isopropoksida [ $\left.\mathrm{Ti}\left(\mathrm{OC}_{3} \mathrm{H}_{7}\right)_{4}\right]$ dengan kemurnian $97 \%$ dari SigmaAldrich, 2-propanol pro analisis (isopropanol) 98\% Merck, asam sulfat $\left(\mathrm{H}_{2} \mathrm{SO}_{4}\right) \quad 98 \%$, tween-80 $\left(\mathrm{C}_{64} \mathrm{H}_{124} \mathrm{O}_{26}\right)$ Merck, remazol kuning dan aquades.

Sintesis $\mathrm{S}_{-} \mathrm{TiO}_{2}$ dilakukan melalui pencampuran titanium isopropoksida, isopropanol, tween-80 dan $\mathrm{H}_{2} \mathrm{SO}_{4}$. Dalam hal ini, isopropanol sebagi pelarut dan $\mathrm{H}_{2} \mathrm{SO}_{4}$ sebagai sumber doping sulfur. Proses sintesis dimulai dengan menimbang 8 gram tween-80 menggunakan neraca digital. Kemudian menambahkan $80 \mathrm{ml}$ isopropanol dan diaduk selama 10 menit. Setelah itu menambahkan titanium isopropoksida sebanyak $6,8 \mathrm{ml}$ ke dalam larutan dan dilanjutkan pengadukan selama 20 menit. Kemudian menambahkan $\mathrm{H}_{2} \mathrm{SO}_{4}$ sebanyak $4 \mathrm{ml}$ dengan variasi laju injeksi pada masing-masing sampel $4 \mathrm{ml} / 30$ menit, $4 \mathrm{ml} / 60$ menit, $4 \mathrm{ml} / 90$ menit dan $4 \mathrm{ml} / 120$ menit. Lalu dilanjutkan pengadukan selama 12 jam utuk mencapai homogenitas.

Larutan kemudian dikeringkan dalam oven pada suhu $80{ }^{\circ} \mathrm{C}$ selama 24 jam untuk menghilangkan kadar uap air. Setelah itu dilakukan kalsinasi pada suhu $450{ }^{\circ} \mathrm{C}$ selama 5 jam untuk menghilangkan zat-zat yang tidak diperlukan. Serbuk yang terbentuk kemudian digerus menggunakan mortar akik dan diuji Spektrofotometer UVVis untuk mengetahui aktivitas fotokatalis serta karakterisasi menggunakan TEM untuk melihat ukuran partikel $\mathrm{S}-\mathrm{TiO}_{2}$. Komposisi pada masing-masing sampel ditunjukkan pada Tabel 1. 
Tabel 1. Variasi laju injeksi doping sulfur pada setiap sampel

\begin{tabular}{cccccc}
\hline Sampel & $\begin{array}{c}\text { Tween-80 } \\
(\text { gram })\end{array}$ & $\begin{array}{c}\text { i-PrOH } \\
(\mathrm{ml})\end{array}$ & TTIP $(\mathrm{ml})$ & $\begin{array}{c}\mathrm{H}_{2} \mathrm{SO}_{4} 1 \mathrm{M} \\
(\mathrm{ml})\end{array}$ & $\begin{array}{c}\text { Laju injeksi doping } \\
(\text { menit })\end{array}$ \\
\hline A & 8 & 80 & 6,8 & 4 & - \\
B & 8 & 80 & 6,8 & 4 & 30 \\
C & 8 & 80 & 6,8 & 4 & 60 \\
D & 8 & 80 & 6,8 & 4 & 90 \\
E & 8 & 80 & 6,8 & 4 & 120 \\
\hline
\end{tabular}

Pengujian fotokatalis dilakukan pada larutan remazol kuning $10 \mathrm{ppm}$ dari $3 \mathrm{ml}$ remazol kuning, $297 \mathrm{ml}$ aquabides dan 0,25 gram $\mathrm{TiO}_{2}$ doping sulfur. Ketiga bahan tersebut dicampur dan diaduk hingga larutan homogen. Kemudian dilakukan penyinaran dibawah lampu UV Ultra Vitalux 230 E27 Osram. Selanjutnya, dilakukan pengambilan larutan sebanyak $20 \mathrm{ml}$ setiap 10 menit sebanyak 5 kali. Larutan yang telah disinari kemudian diuji spektrofotometer UV-Vis menggunakan Cary 100 versi 12.00 untuk memperoleh data absorbansi pada panjang gelombang tertentu.

Sedangkan untuk proses karakterisasi TEM diawali dengan mencampurkan sampel dengan dispersan. Terdapat tiga dispersan yang umumnya digunakan antara lain aquabides, etanol dan aseton yang disesuaikan dengan identitas sampel. Selanjutnya, sampel diletakkan pada grid atau substrat yang diketahui memiliki lubang-lubang tak kasat mata. Kemudian sampel siap untuk dikarakterisasi dengan alat TEM. Mula-mula sampel dimasukkan ke dalam alat TEM yang telah divakumkan sebelumnya. Kemudian dilakukan pengaturan tegangan sehingga elektron mampu menembus daerah terang atau lubang-lubang tak kasat mata pada grid. Kemampuan elektron tersebut yang selanjutnya digunakan untuk menunjukkan daerah sampel. Setelah itu, dilakukan penentuan fokus dan daerah yang akan dilakukan pengujian sehingga diperoleh hasil foto dengan skala pengukuran tertentu.

\section{HASIL DAN PEMBAHASAN}

Gambar 1 merupakan hasil pengujian fotokatalis $\mathrm{S}_{-} \mathrm{TiO}_{2}$ menggunakan larutan remazol kuning di bawah lampu UV.

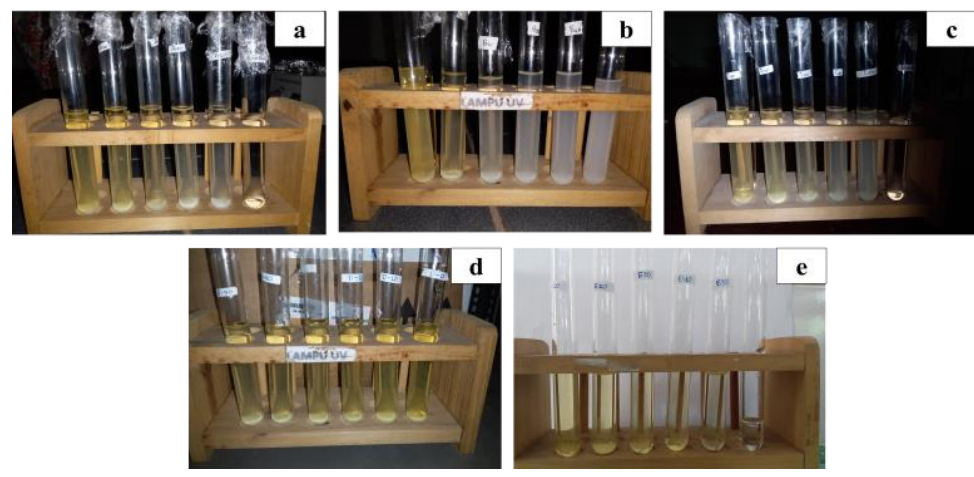

Gambar 1. Hasil uji fotokatalis pendegradasian remazol kuning dibawah lampu UV (a) sampel A (b) sampel B (c) sampel C (d) sampel D dan (e) sampel E 
Gambar 1 menunjukkan hasil pendegradasian larutan remazol kuning di bawah lampu UV selama 50 menit dengan pengambilan setiap 10 menit. Berdasarkan Gambar 1, pendegradasian larutan remazol kuning pada setiap sampel terlihat signifikan terutama pada sampel B yang ditunjukkan oleh adanya perubahan warna larutan seiring dengan lamanya waktu penyinaran menggunakan lampu UV. Dimana warna larutan sebelum dilakukan penyinaran adalah kuning terang dan seiring dengan lamanya waktu penyinaran, warna larutan berubah menjadi putih bening.

Perubahan warna terjadi akibat degradasi zat warna oleh $\mathrm{S}_{-} \mathrm{TiO}_{2}$ sebagai fotokatalis yang merupakan bahan semikonduktor. Semakin bening larutan menunjukkan semakin banyak zat warna yang terdegradasi oleh $\mathrm{S}-\mathrm{TiO}_{2}$ dan semakin tinggi aktivitas fotokatalis $\mathrm{S}_{-} \mathrm{TiO}_{2}$. Sehingga, berdasarkan perubahan warna, sampel B merupakan sampel yang memiliki aktivitas fotokatalis tertinggi.
Proses fotokatalis diawali karena adanya eksitasi elektron dari pita valensi ke pita konduksi pada material semikonduktor ketika dikenai energi dari lampu UV. Ketika semikonduktor $\mathrm{TiO}_{2}$ yang memiliki pita valensi penuh dan pita konduksi kosong disinari panjang gelombang tertentu yang memiliki energi lebih besar dibandingkan celah pita energinya maka elektron $\left(\mathrm{e}^{-}\right)$yang terdapat pada pita valensi akan tereksitasi menuju pita konduksi sehingga meninggalkan lubang $\left(\mathrm{h}^{+}\right)$pada pita valensi.

Kondisi ini memungkinkan interaksi antara pasangan elektron dan lubang dengan zat kimia lain pada permukaan. Kemampuan ini yang dimanfaatkan untuk menyerap senyawa organik seperti zat warna dalam larutan [15].

Degradasi larutan remazol kuning dapat diketahui melalui uji spektrofotometer UV-Vis. Hasil pengujian spektrofotometer UV-Vis ditunjukkan pada Gambar 2.

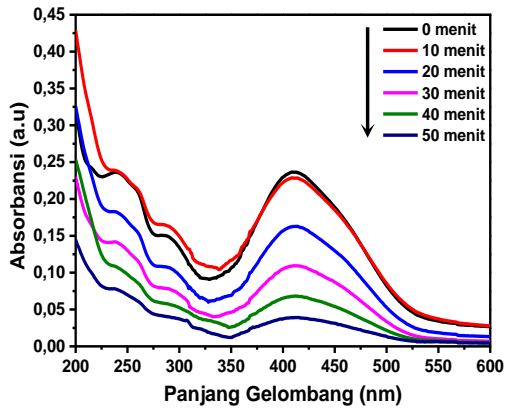

(a)

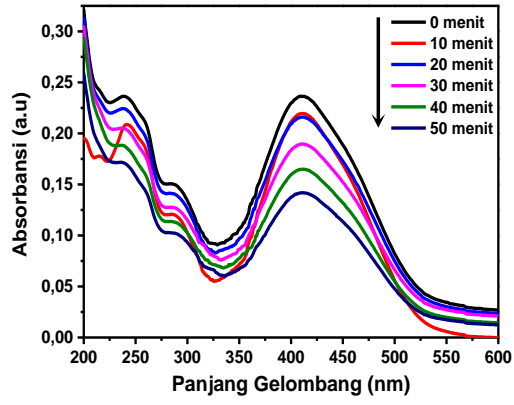

(d)

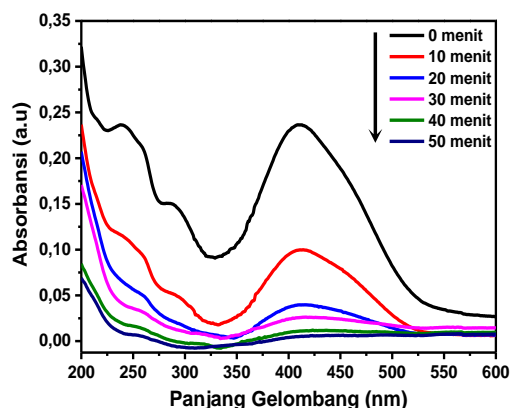

(b)

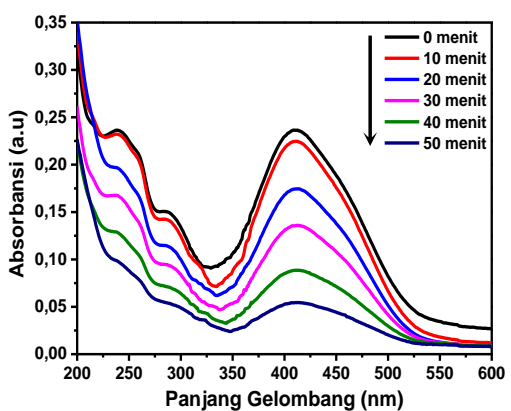

(c)

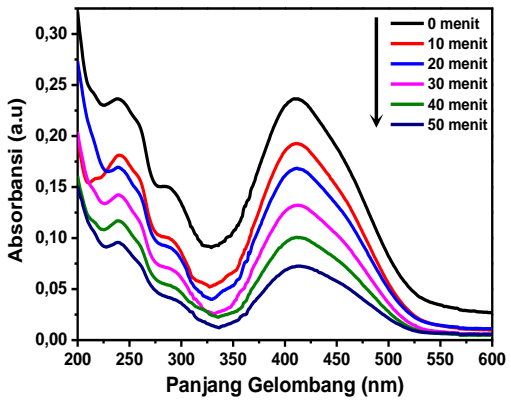

(e)

Gambar 2. Hasil pengulasan spektrofotometri Uv-Vis menggunakan lampu UV (a) sampel A (b) sampel B (c) sampel C (d) sampel D (e) sampel E 
$\begin{array}{crr}\text { Berdasarkan } & \text { hasil pengulasan } \\ \text { spektrofotometer } & \text { UV-Vis } & \text { yang }\end{array}$ diperlihatkan Gambar 2, degradasi warna remazol kuning pasa setiap sampel terjadi secara gradual sesuai dengan lamanya waktu penyinaran dibawah lampu UV. Degradasi remazol kuning diambil pada posisi puncak panjang gelombang maksimum sebesar $411 \mathrm{~nm}$.

Pada sampel B, penurunan nilai absorbansi terjadi lebih cepat pada per 10 menit waktu penyinaran di bawah lampu UV dibandingkan pada sampel A, C, D dan E. Kemudian, nilai absorbansi pada sampel B mencapai 0 pada 50 menit penyinaran yang menunjukkan bahwa zat warna larutan sudah terdegradasi sempurna oleh $\mathrm{S}-\mathrm{TiO}_{2}$ yang menunjukkan adanya peningkatan aktivitas fotokatalis $\mathrm{S}-\mathrm{TiO}_{2}$.

Sedangkan penurunan nilai absorbansi pada hasil pengujian spektrofotometer UvVis pada sampel A, C, D dan E tidak signifikan. Hal ini sesuai dengan hasil pengujian fotokatalis menggunakan larutan remazol kuning di bawah lampu UV yang menunjukkan bahwa perubahan warna larutan pada sampel A, C, D dan E tidak terlihat signifikan. Berikut penurunan nilai absorbansi pada setiap sampel terhadap waktu penyinaran dalam bentuk grafik dapat dilihat pada Gambar 3.

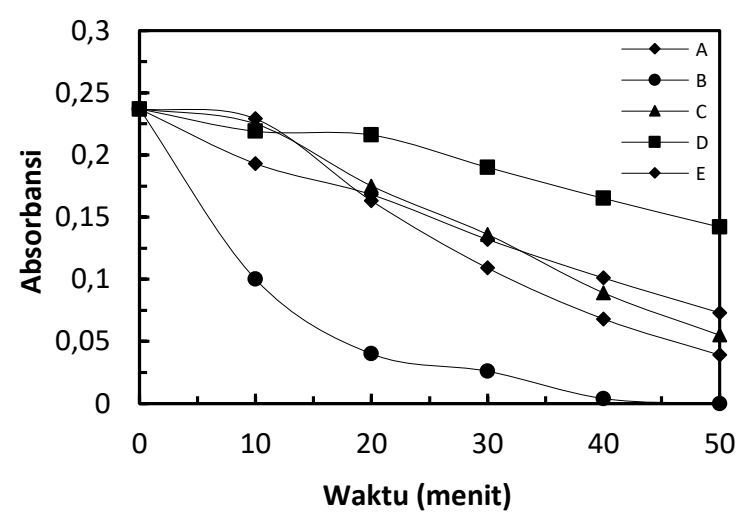

Gambar 3. Nilai absorbansi larutan remazol kuning pada sampel A, B, C, D dan E di bawah lampu UV pada panjang gelombang maksimum $411 \mathrm{~nm}$
Nilai absorbasi terkecil dengan penurunan absorbansi terbesar diperoleh pada sampel B. Hal ini dapat dilihat dari nilai absorbansi pada waktu penyinaran 50 menit, yakni sebesar 0. Nilai ini merupakan nilai absorbansi terkecil dari semua sampel yang ada. Rendahnya nilai absorbansi mengindikasikan bahwa konsentrasi larutan remazol kuning berkurang karena adanya aktivitas fotokatalisis yang tinggi dari sampel B. Sampel B memiliki rata-rata penurunan nilai absorbansi sebesar 0,474.

Penelitian Rafidiyah menunjukkan bahwa $\mathrm{TiO}_{2}$ murni tidak menunjukkan penurunan nilai absorbansi yang signifikan dan apabila dihitung ratarata penurunan nilai absorbansi per 10 menit adalah 0,044. Sedangkan pada penelitian yang dilakukan oleh Fadilah (2015), $\mathrm{TiO}_{2}$ murni memiliki rata-rata penurunan nilai absorbansi per 15 menit adalah 0,0385. Sehingga aktivitas fotokatalis pada sampel $\mathrm{B}$ lebih tinggi dibandingkan dengan $\mathrm{TiO}_{2}$ murni. Dengan demikian, dapat disimpulkan bahwa terjadi peningkatan aktivitas fotokatalis pada sampel $\mathrm{S}-\mathrm{TiO}_{2}$ dengan laju injeksi doping sulfur $4 \mathrm{ml} / 30$ menit.

Hasil analisis morfologi dan distribusi ukuran partikel menggunakan TEM pada sampel B ditunjukkan pada Gambar 4.

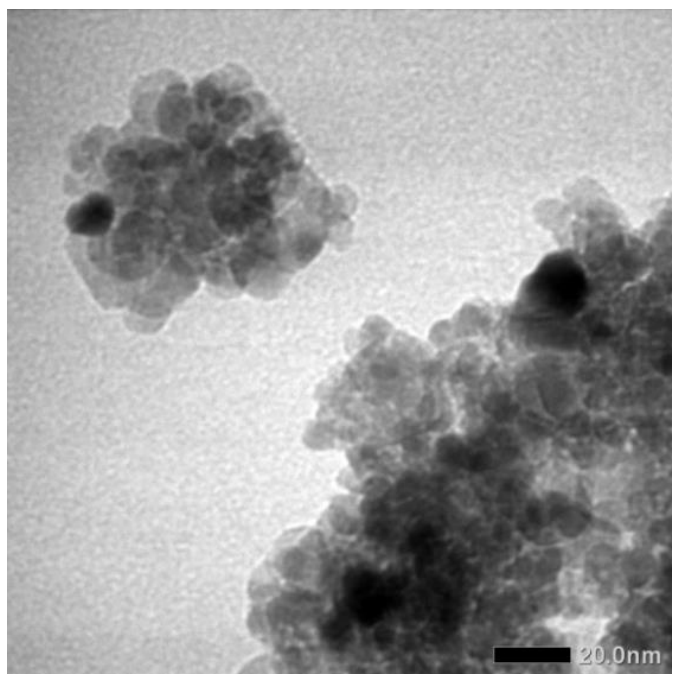

Gambar 4. Hasil analisis TEM pada sampel B 
Hasil analisis TEM yang ditampilkan pada Gambar 4, menunjukkan bahwa nanostruktur sampel laju penambahan doping sulfur 30 menit memiliki bentuk partikel yang tidak teratur namun cenderung bulat, padat serta saling bersentuhan. Selain itu, terdapat beberapa bagian yang terang dan sebagian lainnya gelap serta terlihat adanya adhesi nanopartikel pada sampel.

Berdasarkan pengukuran menggunakan perangkat lunak ImageJ dari beberapa partikel, diperoleh rata-rata ukuran partikel pada sampel B yaitu $(7,1 \mathrm{~nm} \pm 1,9) \mathrm{nm}$. Sehingga, dapat dikatakan bahwa butiran partikel pada sampel B termasuk ke dalam nanomaterial.

Hasil analisis TEM yang ditampilkan pada Gambar 4, menunjukkan bahwa nanostruktur $\mathrm{S}_{-}-\mathrm{TiO}_{2}$ dengan laju penambahan doping sulfur 30 menit memiliki bentuk partikel yang tidak teratur namun cenderung bulat, padat serta saling bersentuhan. Dilakukannya penambahan doping $\mathrm{S}$ dengan laju yang konstan menggunakan pompa injeksi selama 30 menit mempengaruhi ukuran partikel yang dihasilkan.

Hal ini dikarenakan metode sol-gel yang digunakan sebagai metode preparasi sampel $\mathrm{S}-\mathrm{TiO}_{2}$ merupakan metode sintesis yang dipengaruhi oleh laju pengendapan prekursor. Laju pengendapan yang sangat lambat akan memberikan peluang untuk membentuk suatu jaringan yang sangat kecil sehingga memberikan peluang untuk menghasilkan partikel-partikel tunggal yang sangat kecil. Semakin kecil ukuran partikel, maka akan semakin luas permukaan yang kemudian akan berpengaruh pada peningkatan aktivitas fotokatalis.

Berdasarkan pengukuran menggunakan perangkat lunak ImageJ dari beberapa partikel, diperoleh rata-rata ukuran partikel pada sampel B sebesar $(7,1 \mathrm{~nm} \pm 1,9 \mathrm{~nm})$. Sehingga, dapat dikatakan bahwa butiran partikel pada sampel B termasuk kedalam nanopartikel ultra halus.

\section{KESIMPULAN}

Penambahan doping yang dilakukan dengan menggunakan pompa injeksi memiliki pengaruh terhadap peningkatan aktivitas fotokatalis $\mathrm{S}^{-\mathrm{TiO}_{2}}$. Sampel dengan aktivitas fotokatalis tertinggi yaitu sampel laju injeksi $4 \mathrm{ml} / 30$ menit dengan ukuran partikel sebesar $(7,1 \mathrm{~nm} \pm 1,9 \mathrm{~nm})$.

\section{UCAPAN TERIMAKASIH}

Terima kasih kepada Kepala Laboratorium Optik Jurusan Fisika serta Kepala Laboratorium Kimia Fisik dan Anorganik Jurusan Kimia FMIPA Universitas Lampung yang telah memfasilitasi laboratorium.

\section{DAFTAR PUSTAKA}

[1] D. R. Tobergte and S. Curtis, "Sintesis dan Karakterisasi Superkapasitor Berbasis Nanokomposit $\mathrm{TiO}_{2} / \mathrm{C}$, J. Chem. Inf. Model., vol. 53, no. 9, pp. 16891699, 2013.

[2] K. Thamaphat, P. Limsuwan, and B. Ngotawornchai, " $\mathrm{TiO}_{2} \quad$ XRD Pattern", vol. 361, pp. 357-361, 2008.

[3] N. T. Nolan, M. K. Seery, and S. C. Pillai, "Spectroscopic investigation of the anatase to rutile transformation of sol gel synthesized $\mathrm{TiO}_{2}$ photocatalysts", J. Phys. Chem. C, vol. 113, no. 36, pp. 16151-16157, 2009.

[4] K. Nishizawa, M. Okada, and E. Watanabe, "New Preparation Method of Visible Light Responsive Titanium Dioxide Photocatalytic Films", Mater. Sci. Appl., vol. 05, no. 03, pp. 112-123, 2014. 
[5] R. K. Wahi et al., "Photodegradation of Congo Red catalyzed by nanosized $\mathrm{TiO}_{2}$ ", J. Mol. Catal. A Chem., vol. 242, no. 1-2, pp. 48-56, 2005.

[6] E. M. Rockafellow, L. K. Stewart, and W. S. Jenks, "Is sulfur-doped $\mathrm{TiO}_{2}$ an effective visible light photocatalyst for remediation?", Appl. Catal. B Environ., vol. 91, no. 1-2, pp. 554-562, 2009.

[7] M. Stucchi et al., "Surface decoration of commercial microsized $\mathrm{TiO}_{2}$ by means of high energy ultrasound: A way to enhance its photocatalytic activity under visible light", Appl. Catal. B Environ., vol. 178, pp. 124-132, 2014.

[8] M. Pelaez et al., "A review on the visible light active titanium dioxide photocatalysts for environmental applications", Appl. Catal. B Environ., vol. 125, pp. 331-349, 2012.

[9] K. J. A. Raj and B. Viswanathan, "Effect of surface area, pore volume and particle size of P25 titania on the phase transformation of anatase to rutile", Indian J. Chem. Sect. A Inorganic, Phys. Theor. Anal. Chem., vol. 48, no. 10, pp. 1378-1382, 2009.
[10] L. Mao, Q. Li, H. Dang, and Z. Zhang, "Synthesis of nanocrystalline $\mathrm{TiO}_{2}$ with high photoactivity and large specific surface area by sol-gel method", Mater. Res. Bull., vol. 40, no. 2, pp. 201-208, 2005.

[11] W. Yu et al., "Enhanced visible light photocatalytic degradation of methylene blueby F-doped $\mathrm{TiO}_{2}$, Appl. Surf. Sci., vol. 319, no. 1, pp. 107-112, 2014.

[12] M. Haadanian, A. Reisi-Vanani, and A. Majedi, "Preparation and characterization of S-doped $\mathrm{TiO}_{2}$ nanoparticles, effect of calcination temperature and evaluation of photocatalytic activity", Mater. Chem. Phys., vol. 116, no. 2-3, pp. 376-382, 2009.

[13] S. Fadilah, P. Manurung, and E. Ginting, "Pengaruh titania yang didoping sulfur terhadap ukuran partikel", vol. 04, no. 01, pp. 37-42, 2016.

[14] T. Ohno, T. Mitsui, and M. Matsumura, "Photocatalytic Activity of S-doped $\mathrm{TiO}_{2}$ Photocatalyst under Visible Light", Chem. Lett., vol. 32, no. 4, pp. 364-365, 2003.

[15] U. Diebold, "The surface science of titanium dioxide", Surface Science Report, vol. 48, 2002. 
Amrani dkk: Pengaruh Laju Penginjeksian Doping Sulfur terhadap Aktivitas Fotokatalis Nanotitania Menggunakan Metode Sol Gel 